Open Access

\title{
Incidence of pain flare following palliative radiotherapy for symptomatic bone metastases: multicenter prospective observational study
}

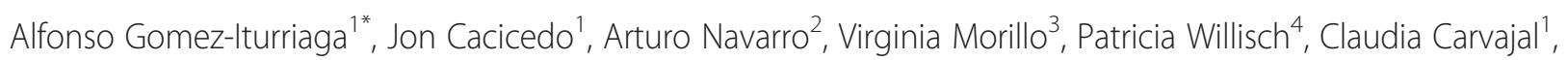
Eduardo Hortelano', Jose Luis Lopez-Guerra ${ }^{5}$, Ana Illescas ${ }^{6}$, Francisco Casquero ${ }^{1}$, Olga Del Hoyo ${ }^{1}$, Raquel Ciervide ${ }^{7}$, Ana Irasarri ${ }^{8}$, Jose Ignacio Pijoan ${ }^{8}$ and Pedro Bilbao ${ }^{1}$

\begin{abstract}
Background: Palliative radiotherapy (RT) is an effective treatment for symptomatic bone metastases. Pain flare, a transient worsening of the bone pain after RT, has been described in previous reports with different incidence rates. The aim of the study was to prospectively evaluate the incidence of pain flare following RT for painful bone metastases and evaluate its effects on pain control and functionality of the patients.

Methods: Between June 2010 and June 2014, 204 patients were enrolled in this study and 135 patients with complete data were evaluable. Pain flare was defined as a 2-point increase in worst pain score as compared with baseline with no decrease in analgesic intake or a $25 \%$ increase in analgesic intake as compared with baseline with no decrease in worst pain score. All pain medications and worst pain scores were collected before, daily during, and for 10 days after RT. The Brief Pain Inventory (BPI) was filled out on the pretreatment and at the 4 weeks follow-up visit.
\end{abstract}

Results: There were 90 men (66.7 \%) and 45 women (33.3\%). Mean age was 66 years (SD 9.8). The most common primary cancer site was lung in 42 patients (31.1\%), followed by prostate in 27 patients (20.0\%). Forty-two patients (31.1\%) patients received a single fraction of 8 Gy and 83 (61.5\%) received 20 Gy in five fractions.

The overall pain flare incidence across all centers was 51/135 (37.7\%). The majority of pain flares occurred on days 1-5 (88.2 \%). The mean duration of the pain flare was 3 days (SD: 3$)$. There were no significant relationships between the occurrence of pain flare and collected variables.

All BPI items measured four weeks after end of RT showed significant improvement as compared with pretreatment scores $(p<0.001)$. No significant differences in BPI time trends were found between patients with and without flare pain.

Conclusion: Pain flare is a common event, occurring in nearly $40 \%$ of the patients that receive palliative RT for symptomatic bone metastases. This phenomenon is not a predictor for pain response.

Keywords: Pain flare, Palliative radiotherapy, Bone metastases

\footnotetext{
*Correspondence: agomeziturriaga@gmail.com

'Department of Radiation Oncology, Hospital Universitario Cruces/ Biocruces

Health Research Institute, Plaza Cruces 12, 48903 Barakaldo, Spain

Full list of author information is available at the end of the article
}

(c) 2015 Gomez-Iturriaga et al. Open Access This article is distributed under the terms of the Creative Commons Attribution 4.0 International License (http://creativecommons.org/licenses/by/4.0/), which permits unrestricted use, distribution, and reproduction in any medium, provided you give appropriate credit to the original author(s) and the source, provide a link to the Creative Commons license, and indicate if changes were made. The Creative Commons Public Domain Dedication waiver (http://creativecommons.org/publicdomain/zero/1.0/) applies to the data made available in this article, unless otherwise stated. 


\section{Background}

Bone metastases are a common distance manifestation in advanced oncologic patients with a rising incidence due to longer survival of cancer patients. It is the most common cause of cancer-related pain and the most frequent symptom that requires treatment in cancer patients [1].

Palliative radiotherapy (RT) is a well-established and effective treatment alternative for symptomatic bone metastases. Depending on the criteria used, complete response of the pain could be achieved from $10 \%$ to $35 \%$ of patients, with overall pain response rates approaching $70 \%[2]$.

Several randomized controlled trials (RCT) [3-7] and three meta-analysis [8-10] have shown equivalent pain response rates for single- and multiple-fraction radiotherapy treatments in the palliation of painful bone metastases.

Although RT for bone metastases is associated with limited side effects, a transitory aggravation of bone pain after treatment in the irradiated site has been recognized in several published reports, with published incidence rates of this phenomenon varying between $2 \%$ and $40 \%$ [11-13].

To date, the evidence in the literature evaluating prospectively the incidence of pain flare is scarce. Few prospective observational studies, with a low number of patients, have explored the incidence of pain flare [12, 14]. These studies have also demonstrated that pain flare associated with RT negatively impacts on the functionality and the mood of the patients.

Therefore, the objectives of this prospective multicenter observational study were to determine the incidence of pain flare after palliative radiation for painful bone metastases and to evaluate the impact of the pain flare on the pain control and the functionality of the patients.

\section{Methods and Materials}

Subjects eligible for the study were patients with bone metastases treated with External Beam RT. Criteria for patient eligibility were: age 18 years or older with radiological evidence of bone metastases from a solid tumor, single lesion or multiple metastases were both accepted, pain intensity attributable to the bone lesion measured by Visual Analogue Scale (VAS) of $0-10$ and patients capability and willingness to sign informed consent and complete the daily diary.

The radiation dose schedules permitted in the study were those administering 8 to 20 Gy in 1 to 5 daily fractions.

The protocol was initially approved by the Ethics Committee of the coordinating center (Hospital Universitario Cruces ), and ethics approval was subsequently requested and obtained at each participating center (Hospital Ramón y Cajal, Hospital Meixoeiro, Hospital Universitario Virgen de la Macarena, Hospital Gregorio Marañon, ICO- Instituto Catalan de Oncologia, Hospital Universitario Reina Sofia, Hospital Provincial Castellon, Hospital Sanchinarro, Hospital Virgen del Rocio).

\section{Patient evaluation}

The pre-treatment evaluation consisted of a full history and physical examination, administration of Brief Pain Inventory (BPI), record of analgesic consumption within the previous $24 \mathrm{~h}$ and provision of the patient's diary with oral and written instructions on how to fill it on a daily basis during treatment and 10 days after termination of RT. This diary recorded worst pain scores (on a numerical rating scale from $0-10$ ), analgesic usage (total intake of analgesic medication in the 24 hour-period) and pain perception as compared with baseline pain (worse, better or same).

A follow-up visit was scheduled 4-weeks after the end of the RT. At this time the BPI was again administered, and analgesic consumption within the previous 24 hours was recorded.

\section{Treatment response}

Pain response was measured using the International Bone Metastases Consensus from 2002 [15]. Complete response was defined as a pain score of zero at the bony metastatic site with no concomitant increase in analgesic intake. Partial response was defined as any of the following: a) pain reduction of two or more points below baseline score, at the bony metastatic site on a $0-10$ scale without analgesic increase or $b$ ) analgesic reduction of $25 \%$ or more from baseline without an increase in pain with reference to baseline. Pain progression was defined as an increase of pain score of two or more points above baseline at the bony metastatic site with stable analgesic use or an increase of $25 \%$ or more daily OMED compared with baseline with pain score stable or one point above baseline. Patients not meeting these criteria were classified as having stable disease.

\section{Pain flare evaluation}

Since most previous studies concerning pain flare have used the definition by Chow [11], we also chose to use this definition in order to enable comparisons with other studies.

Pain flare was defined (a priori) as any two-point increase of the pain scale of $0-10$ in the daily diary compared to baseline levels with no decrease in analgesic intake or a $25 \%$ increase in analgesic intake employing daily OMED with no decrease in pain score. If the baseline pain was nine, pain flare was defined if the follow up pain score was 10 accompanied with a response of 
current pain perception worse than the baseline pain. If the baseline pain was 10, pain flare was defined if the follow up pain score was 10 with current pain perception as worse than the baseline pain. To distinguish pain flare from progression of pain, we required the pain score and analgesic intake to return back to baseline after the flare [11].

\section{Statistical analysis}

Descriptive statistics were used for demographic, clinical and treatment characteristics.

Continuous variables are expressed as the mean and standard deviation or median and range for quantitative variables, depending on distributional characteristics, whereas categorical variables are presented as frequencies and percentages.

Associations between categorical variables were assessed using Chi square or Fisher exact tests depending upon expected cell frequencies.

To assess changes in BPI items scoring between follow-up and baseline visit, T-tests for paired samples were used. To compare changes of BPI scores over time between patients with and without pain flare, T-tests for independent samples were used. All statistical analyses were conducted using SPSS v22 for Windows (IBM Corp. Released 2013. IBM SPSS Statistics for Windows,
Version 22.0. Armonk, NY: IBM Corp). Statistical significance threshold was set at $5 \%$.

\section{Results}

Between June 2010 and June 2014, 204 patients from ten Radiation Oncology Departments in Spain participated in this prospective observational study. From this cohort, 135 patients (66.2 \%) completed the daily diary, 127 patients $(62.2 \%)$ the 4-weeks follow-up visit and 118 patients $(57.8 \%)$ completed both, the daily diary and the follow-up visit. These patients are labeled as evaluable patients and are the subject of statistical analysis. Reasons for incomplete data are: 25 patients experienced a deterioration in their performance status, 21 patients did not complete the pain diary, there were 16 unknown reasons for incomplete data and 15 patients requested removal from the study.

The relevant demographic, clinical and treatment characteristics of evaluable and no evaluable patients are shown in Table 1.

Based on the Chow definition [11], 51 of the 135 evaluable patients $(37.7 \%)$ presented pain flare. Pain flare occurred between days $1-5$ after RT in $45 / 51$ patients $(88.2 \%)$ and between days $6-15$ in $6 / 51$ patients $(11.8 \%)$ (Fig. 1). The mean duration of the flare was 3 days (SD 3).

Table 1 Main demographic, clinical and treatment characteristics.

\begin{tabular}{|c|c|c|c|}
\hline & & Evaluable Patients $(N=135)$ & No Evaluable Patients $(N=69)$ \\
\hline Age (years) & Mean (SD) & $66.6(12.4)$ & $65.6(11.1)$ \\
\hline \multirow[t]{2}{*}{ Gender } & Male & $90(66.7 \%)$ & $45(65.2 \%)$ \\
\hline & Female & $45(33.3 \%)$ & 24(34.8 \%) \\
\hline \multirow[t]{4}{*}{ Primary cancer site } & Lung & $42(31.1 \%)$ & $21(30.4 \%)$ \\
\hline & Prostate & $27(20.0 \%)$ & $10(14.5 \%)$ \\
\hline & Breast & 19 (14.1\%) & $5(7.3 \%)$ \\
\hline & Others & $47(34.8 \%)$ & $33(47.8 \%)$ \\
\hline Worst pain ${ }^{a}$ & Median (range) & $8(0-10)$ & $8(0-10)$ \\
\hline \multirow[t]{3}{*}{ RT dose } & $5 \times 400$ cGy & $83(61.5 \%)$ & $40(58.0 \%)$ \\
\hline & 1 x 800 cGy & $42(31.1 \%)$ & $20(29.0 \%)$ \\
\hline & Other & $10(7.4 \%)$ & $9(13.0 \%)$ \\
\hline \multirow[t]{4}{*}{ RT site } & Pelvis & $57(42.2 \%)$ & $21(32.8 \%)$ \\
\hline & Spine & $39(28.9 \%)$ & 25(39.1\%) \\
\hline & Extremities & $20(14.8 \%)$ & $11(17.2 \%)$ \\
\hline & Others & 19 (14.1\%) & 7(10.9\%) \\
\hline \multirow[t]{2}{*}{ Bisphosphonates } & YES & $36(26.7 \%)$ & $16(23.2 \%)$ \\
\hline & NO & $99(73.3 \%)$ & $53(76.8 \%)$ \\
\hline \multirow[t]{2}{*}{ Dexamethasone } & YES & $41(30.8 \%)$ & $17(26.6 \%)$ \\
\hline & $\mathrm{NO}$ & 92 (69.2\%) & $47(73.4 \%)$ \\
\hline
\end{tabular}




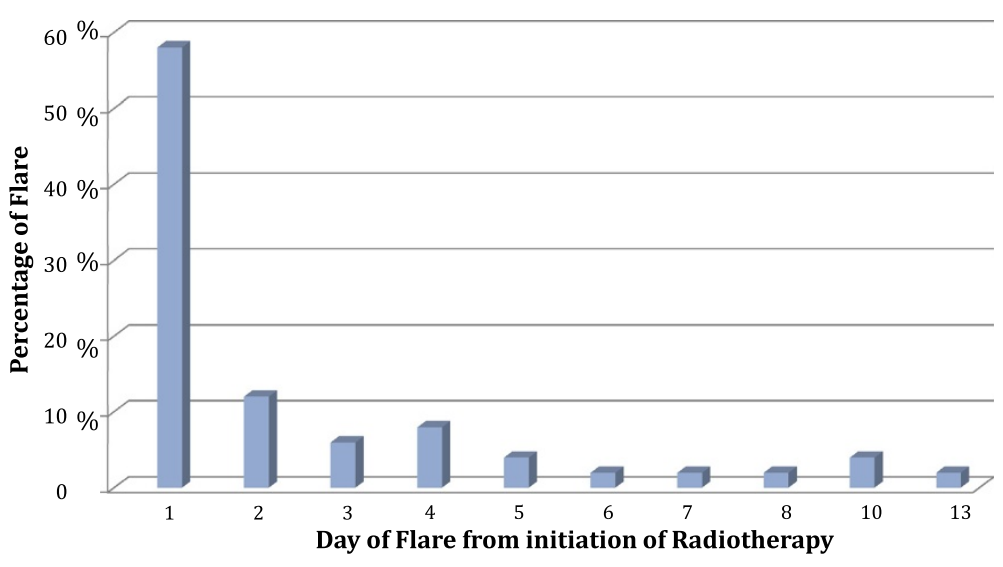

Fig. 1 Distribution of pain flare events from the date of initiation of Radiotherapy

Pain response to RT at 4 weeks was available for 127 of the 135 assessable cases. Fifteen patients (11.8\%) achieved a complete response and 64 (50.4\%) a partial response. Stable disease was found in 34 patients $(26.8 \%)$ and pain progression in 14 (11\%).

No significant relationships were found between the occurrence of pain flare and baseline variables, such as gender type, radiation dose, radiation site, primary cancer site, bisphosphonates use and dexamethasone use (Table 2).

Changes in the BPI scores were assessed at 4 weeks after RT. For evaluation purposes, the BPI responses were assigned to two different dimensions, pain severity (sensory dimension of the pain) and pain interference (reactive dimension). There was a significant reduction in all BPI scores after RT $(p<0.001)$. A median decrease of 4 points compared to the pretreatment setting was found for the "worst pain", "activity", "mood", "walking ability" and "normal work" domains.

There were not significant differences in BPI changes between baseline and 4 weeks follow-up visits between patients with or without flare effect.

The BPI scores for those who responded (CR or PR) were compared with those who did not respond (SD or $\mathrm{PD})$ to RT. There was a significant difference between the two groups in all functional interference items $(p<0.05)$ except for sleep $(p=0.549)$.

At 4 weeks, $70.8 \%$ of evaluable patients with pain flare and $58.6 \%$ of evaluable patients without flare were responders, respectively $(\mathrm{p}=0.174)$.

Table 2 Relationships between the occurrence of pain flare and baseline variables $(n=135)$

\begin{tabular}{|c|c|c|c|c|}
\hline & & \multicolumn{2}{|l|}{ FLARE } & \multirow[b]{3}{*}{$p$-value* } \\
\hline & & \multirow{2}{*}{$\begin{array}{l}\text { NO } \\
\text { N (\%) }\end{array}$} & \multirow{2}{*}{$\begin{array}{l}\text { YES } \\
\text { N (\%) }\end{array}$} & \\
\hline & & & & \\
\hline \multirow[t]{2}{*}{ Sex } & Male & $55(61.1 \%)$ & $35(38.9 \%)$ & \multirow[t]{2}{*}{$p=0.70$} \\
\hline & Female & $29(64.4 \%)$ & $16(35.6 \%)$ & \\
\hline \multirow[t]{4}{*}{ Cancer Site } & Lung & $23(54.8 \%)$ & $19(45.2 \%)$ & \multirow[t]{4}{*}{$p=0.358$} \\
\hline & Prostate & $16(59.3 \%)$ & $11(40.7 \%)$ & \\
\hline & Breast & $15(78.9 \%)$ & $4(21.1 \%)$ & \\
\hline & Others & $30(63.8 \%)$ & $17(36.2 \%)$ & \\
\hline \multirow[t]{2}{*}{ Bisphosphonates } & YES & $23(63.9 \%)$ & $13(36.1 \%)$ & \multirow[t]{2}{*}{$p=0.81$} \\
\hline & NO & $61(61.6 \%)$ & $38(38.4 \%)$ & \\
\hline \multirow[t]{3}{*}{ RT Dose } & $8 \mathrm{~Gy} / 1 \mathrm{fx}$ & $28(66.7 \%)$ & $14(33.3 \%)$ & \multirow[t]{3}{*}{$p=0.09$} \\
\hline & 20 Gy / 5 fx & $47(56.6 \%)$ & $36(43.4 \%)$ & \\
\hline & Other & $9(90.0 \%)$ & $1(10.0 \%)$ & \\
\hline \multirow[t]{2}{*}{ Dexamethasone during RT } & YES & $25(56.1 \%)$ & $18(43.9 \%)$ & \multirow[t]{2}{*}{$p=0.379$} \\
\hline & NO & 59 (64.1\%) & 33 (35.9 \%) & \\
\hline
\end{tabular}




\section{Discussion}

This multisite prospective observational study shows that pain flare is a common event after palliative RT for painful bone metastases, affecting to almost $40 \%$ of these patients. To our knowledge the current study is, up to the present time, the largest clinical cohort prospectively followed to determine the incidence and characterize the pain flare phenomenon. The use of a well-defined pain flare definition and the use of OMED values and verbal description of the pain in our investigation may have improved our capacity to identify a flare when compared with previous studies [13, 16].

Published articles have reported a wide range of the flare phenomenon, which vary between $2 \%$ and $40 \%$. This difference could be at least partly explained by inconsistent definitions of pain flare, use of different radiation dose schedules, lack of adjustments for steroid medication or opiate medication, and variations in the time periods at which pain intensity was recorded to capture the flare event [17].

There are several reports $[11,12,14,17]$ specifically aimed at determining the incidence of pain flare (Table 3). Three of these studies used conventional 3DCRT and one of them stereotactic body radiation therapy (SBRT). While on the studies using 3DCRT the incidence was approximately $40 \%[12,14]$, the incidence in the study using SBRT was $68.3 \%$. This large difference in the incidence of pain flare has been postulated to be a result of significantly greater biologically effective doses delivered with SBRT [17].

A study published by Pan et al. [18], found in a secondary analysis of single-institution phase $1 / 2$ trials evaluating SBRT for the treatment of spinal metastases an overall incidence of flare after SBRT for spinal metastases of $23 \%$. A significant limitation of this study is that the trials were designed to investigate longer term symptomatic and tumor control outcomes instead of acute pain flare; hence, comparison between the studies is limited by differences in study design and population. Moreover, a recent study examining the Mayo Clinic experience of patients treated with SBRT to non-spine bony metastasis, found that only $10 \%$ of the patients presented pain flare. Unfortunately, the flare definition used, the analgesic consumption pattern and the number of patients that received corticosteroids are unknown [19].

The pain flare incidence observed in the studies mentioned is higher than might be expected from clinical experience. In the study published by Chow et al. [11], there was an occurrence of $2 \%-16 \%$, but subsequent reports by Loblaw et al. [12] and by Hird et al. [14] demonstrated pain flare rates of $40 \%$. This is comparable to what we have found in our study.

Based on our results apparently the advent of the pain flare is more common in the first days after the initiation of RT. Indeed, the flare occurred between days 1-5 after RT in $45 / 51$ patients $(88.2 \%)$ and between days $6-15$ in 6/51 patients (11.8\%). Hird et al. [14] reported similar results with $80 \%$ of the patients presenting the flare within days $1-5$ after the RT.

The physiopathology of the pain flare is largely unknown. It has been suggested to arise through edema of the periostium of the irradiated bone resulting in nerve compression or the release of inflammatory cytokines [20]. Thus, dexamethasone has shown potential for preventing this event. Two phase II studies, reporting on the effect of dexamethasone on the incidence of pain flare have been published [21, 22]; both studies reported rates of $24 \%$ and $22 \%$ respectively. In addition, recently, a phase III trial from Egypt has been published investigating the role of dexamethasone to prevent the flare phenomenon. They reported significant differences

Table 3 Published studies evaluating prospectively the incidence of Pain Flare

\begin{tabular}{|c|c|c|c|c|}
\hline Author & Number of evaluable patients & RT technique & RT dose schedules (Gy/fx) & Pain Flare Incidence (\%) \\
\hline \multirow[t]{3}{*}{ Chow } & 88 & 3DCRT & $8 \mathrm{~Gy} / 1 \mathrm{fx}$ & $2-16 \%$ \\
\hline & & & 20 Gy $5 \mathrm{fx}$ & \\
\hline & & & $30 \mathrm{~Gy} / 10 \mathrm{fx}$ & \\
\hline \multirow[t]{2}{*}{ Loblaw } & 44 & 3DCRT & $8 \mathrm{~Gy} / \mathrm{fx}$ & $40.9 \%$ \\
\hline & & & $20 \mathrm{~Gy} / 5 \mathrm{fx}$ & \\
\hline \multirow[t]{3}{*}{ Hird } & 111 & 3DCRT & $8 \mathrm{~Gy} / 1 \mathrm{fx}$ & $40 \%$ \\
\hline & & & 20 Gy $5 \mathrm{fx}$ & \\
\hline & & & 30 Gy /10 fx & \\
\hline \multirow[t]{2}{*}{ Chiang } & 41 & SBRT & 20-24 Gy / 1 fx & $68.3 \%$ \\
\hline & & & 24-35 Gy / 2-5 fx & \\
\hline \multirow[t]{2}{*}{ Gomez-Iturriaga } & 135 & 3DCRT & $8 G y / f x$ & $37.7 \%$ \\
\hline & & & $20 \mathrm{~Gy} / 5 \mathrm{fx}$ & \\
\hline
\end{tabular}


between groups, $16.2 \%$ incidence in the dexamethasone group versus $38 \%$ in the group without steroids $(\mathrm{p}=0.0033)$ [23]. By contrast, in our study we have not found differences in pain flare incidence in favor of the patients who received corticosteroids. In order to explain these divergent findings, we must first acknowledge that our observational study was not specifically designed to address this issue. Moreover, less than half of our population received dexamethasone during RT (Table 2).

There is an ongoing RCT comparing two different dose schedules of dexamethasone and placebo led by the University Medical Center Utrecht. With an accrual goal of 411 patients, this study will help elucidate whether dexamethasone is an effective option in the prevention of pain flare after palliative radiotherapy for bone metastases [24].

Regarding pain response to RT, we found similar response rates to those reported by a range of RCT evaluating response to RT with different dose schedules. Foro [16], Chow [2], Hartsell [25] and Van der Linden [26] reported complete response rates ranging between $11 \%$ and $25 \%$, partial responses between $26 \%$ and $52 \%$, and overall response rates between $46 \%$ and $72 \%$. Despite the elevated incidence of flare our results demonstrate $12 \%$ of complete responses and $50 \%$ of partial responses.

A secondary objective of our study was to evaluate the impact of the palliative radiotherapy on the pain control and the functional ability of the patients. The BPI is a well-known instrument, and has been shown to be a reliable and valid tool in depicting pain severity and the extent to which pain from bone metastases interferes with patient functioning. In the present study, significant changes in all BPI scores were found over time, decreasing from baseline to week 4 .

Nguyen et al. [27] found in a study evaluating pain response and interference using BPI at 1,3 and 6 months, that mood was significantly improved in patients responding to RT and a trend in improvement was observed for general activity and normal work. Another study by Wu et al. [28], in 109 patients who completed BPI after palliative RT for painful bone lesions at 4 and 6 weeks, reported a reduction for all seven functional interference items, with greatest improvement in general activity.

In our study we have found a significant difference in all BPI items after RT $(\mathrm{p}<0.001)$ with larger difference (4 points) for the "activity", "mood", "walking ability" and "normal work" domains.

Most importantly, these observed significant differences in BPI items after RT have real impact on quality of life (QOL) and function, and provide clinically meaningful data to guide clinical decision-making [29].
In the interpretation of this study some limitations are acknowledged. These include a small sample size of 204 patients recruited and a reduction of the effective sample for final analysis to 135 patients. Loss to follow-up is a common problem in patients with metastatic disease. Furthermore, the limited BPI follow-up of 4 weeks after radiation impedes evaluation of long-term outcomes.

Our study demonstrates that pain flare is a common event in patients that receive palliative RT for bone metastases. Despite its frequency, it does not seem to have detrimental effect on the degree of pain control at 4 weeks. Our study has shown high rates of pain response and more importantly, a significant improvement on the functional interference dimension. Further studies evaluating whether simple interventions, such as prophylactic dexamethasone or short-acting opioids contribute to the prevention or amelioration of the flare phenomenon are warranted.

\section{Conclusion}

Pain flare is a common event, occurring in almost $40 \%$ of the patients that receive palliative RT for symptomatic bone metastases. RT for symptomatic bone metastases is a very effective palliative treatment, in terms of pain control and functional interference, even if the patient experiences in the short-term a pain flare.

\section{Abbreviations}

BPI: Brief Pain Inventory; CR: Complete response; OMED: Oral Morphine Equivalent Dose; PR: Partial response; PD: Pain progression; QOL: Quality of life; RT: Radiotherapy; RCT: Randomized Controlled Trials; SBRT: Stereotactic body radiation therapy; SD: Stable disease; VAS: Visual Analogue Scale; 3DCRT: 3D conformal radiotherapy.

\section{Competing interests}

The authors declare that they have no competing interest.

\section{Authors`Contributions}

$A G l, J C$ designed the study and the analysis. AGI, JC, AN, JLG, CC, OH, EH, PB, $\mathrm{RC}, \mathrm{Al}, \mathrm{PW}, \mathrm{FC}, \mathrm{VM}$ collected de clinical data. AGI, Al, JP contributed to interpretation of data. All authors have given final approval of the manuscript.

\section{Authors' information}

Not applicable.

\section{Acknowledgements}

This study was supported by the Health Department of Basque Government Research Grant (RECORD NUMBER: 2010111072) and a FIS Carlos III Health Institute Grant (RECORD NUMBER: PI11/01930).

\section{Author details}

'Department of Radiation Oncology, Hospital Universitario Cruces/ Biocruces Health Research Institute, Plaza Cruces 12, 48903 Barakaldo, Spain.

${ }^{2}$ Department of Radiation Oncology, Instituto Catalan de Oncología, Avinguda de la Gran via de l'Hospitalet, 199-203, 08907 L'Hospitalet de Llobregat, Barcelona, Spain. ${ }^{3}$ Department of Radiation Oncology, Hospital de Castellón, Carrer de les Useres, 1, 12006 Castelló de la Plana, Castelló, Spain. ${ }^{4}$ Department of Radiation Oncology, Hospital Meixoeiro, Meixoeiro, s/n, 36200 Vigo, Pontevedra, Spain. ${ }^{5}$ Department of Radiation Oncology, Hospital Virgen Del Rocío, Av Manuel Siurot, s/n, 41013 Sevilla, Spain. ${ }^{6}$ Department of Radiation Oncology, Hospital Virgen Macarena, Avd. Dr Fedriani, 3, 41071 Sevilla, Spain. ${ }^{7}$ Department of Radiation Oncology, Hospital San Chinarro, 
C/ Oña, 10, 28050 Madrid, Spain. ${ }^{8}$ Clinical Epidemiology Unit, Hospital Universitario Cruces/ Biocruces Heatlh Research Institute, Plaza Cruces 12, 48903 Barakaldo, Spain.

Received: 14 May 2015 Accepted: 24 September 2015

Published online: 01 October 2015

\section{References}

1. Foley KM. The treatment of cancer pain. N Engl J Med. 1985;313:84-95

2. Chow E, Wong R, Hruby G, et al. Prospective patient-based assessment of effectiveness of palliative radiotherapy for bone metastases. Radiother Oncol. 2001;61:77-82.

3. Nielsen OS, Bentzen SM, Sandberg E, et al. Randomized trial of single dose versus fractionated palliative radiotherapy of bone metastases. Radiother Oncol. 1998:47:233-40

4. Price $\mathrm{P}$, Hoskin PJ, Easton D, et al. Prospective randomised trial of single and multifraction radiotherapy schedules in the treatment of painful bony metastases. Radiother Oncol. 1986;6:247-55.

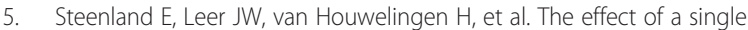
fraction compared to multiple fractions on painful bone metastases: a global analysis of the Dutch Bone Metastasis Study. Radiother Oncol. 1999:52:101-9.

6. Gaze MN, Kelly CG, Kerr GR, et al. Pain relief and quality of life following radiotherapy for bone metastases: a randomised trial of two fractionation schedules. Radiother Oncol. 1997;45:109-16.

7. Cole DJ. A randomized trial of a single treatment versus conventional fractionation in the palliative radiotherapy of painful bone metastases. Clin Oncol (R Coll Radiol). 1989;1:59-62.

8. Chow E, Harris K, Fan G, et al. Palliative radiotherapy trials for bone metastases: a systematic review. J Clin Oncol. 2007;25:1423-36.

9. Wu JS, Wong $\mathrm{R}$, Johnston $\mathrm{M}$, et al. Meta-analysis of dose-fractionation radiotherapy trials for the palliation of painful bone metastases. Int J Radiat Oncol Biol Phys. 2003;55:594-605.

10. Sze WM, Shelley M, Held I, et al. Palliation of metastatic bone pain: single fraction versus multifraction radiotherapy - a systematic review of the randomised trials. Cochrane Database Syst Rev. 2004;2:CD004721.

11. Chow $E$, Ling $A$, Davis $L$, et al. Pain flare following external beam radiotherapy and meaningful change in pain scores in the treatment of bone metastases. Radiother Oncol. 2005:75:64-9.

12. Loblaw D, Wu J, Kirkbride $P$, et al. Pain flare in patients with bone metastases after palliative radiotherapy-a nested randomized control trial. Support Care Cancer. 2007;15:451-5

13. Roos D, Turner S, O'Brien P, et al. Randomized trial of 8 Gy in 1 versus $20 \mathrm{~Gy}$ in 5 fractions of radiotherapy for neuropathic pain due to bone metastases (Trans-Tasman Radiation Oncology Group, TROG 96.05). Radiother Oncol. 2005;75:54-63.

14. Hird A, Chow E, Zhang $L$, et al. Determining the incidence of pain flare following palliative radiotherapy for symptomatic bone metastases: results from three canadian cancer centers. Int J Radiat Oncol Biol Phys. 2009:75:193-7.

15. Chow E, Wu JS, Hoskin $P$, et al. International consensus on palliative radiotherapy endpoints for future clinical trials in bone metastases. Radiother Oncol. 2002;64:275-80.

16. Foro Arnalot P, Fontanals AV, Galceran JC, et al. Randomized clinical trial with two palliative radiotherapy regimens in painful bone metastases: $30 \mathrm{~Gy}$ in 10 fractions compared with $8 \mathrm{~Gy}$ in single fraction. Radiother Oncol. 2008;89:150-5.

17. Chiang $A$, Zeng $L$, Zhang $L$, et al. Pain flare is a common adverse event in steroid-naive patients after spine stereotactic body radiation therapy: a prospective clinical trial. Int J Radiat Oncol Biol Phys. 2013:86:638-42.

18. Pan HY, Allen PK, Wang XS, et al. Incidence and predictive factors of pain flare after spine stereotactic body radiation therapy: secondary analysis of phase 1/2 trials. Int J Radiat Oncol Biol Phys. 2014;90:870-6.

19. Owen D, Laack NN, Mayo CS, et al. Outcomes and toxicities of stereotactic body radiation therapy for non-spine bone oligometastases. Pract Radiat Oncol. 2014:4:e143-149.

20. Svendsen KB, Andersen S, Arnason S, et al. Breakthrough pain in malignant and non-malignant diseases: a review of prevalence, characteristics and mechanisms. Eur J Pain. 2005:9:195-206.
21. Hird A, Zhang L, Holt T, et al. Dexamethasone for the prophylaxis of radiation-induced pain flare after palliative radiotherapy for symptomatic bone metastases: a phase II study. Clin Oncol (R Coll Radiol). 2009;21:329-35.

22. Chow E, Loblaw A, Harris K, et al. Dexamethasone for the prophylaxis of radiation-induced pain flare after palliative radiotherapy for bone metastases: a pilot study. Support Care Cancer. 2007:15:643-7.

23. Sayed MM. The Effect of Systemic Steroids on the Incidence of Bone Pain Flare with Palliative Irradiation. Middle East Journal of Cancer. 2014:5:83-89.

24. Westhoff PG, de Graeff A, Geerling Jl, et al. Dexamethasone for the prevention of a pain flare after palliative radiotherapy for painful bone metastases: a multicenter double-blind placebo-controlled randomized trial. BMC Cancer. 2014;14:347

25. Hartsell W, Scott C, Bruner D, et al. Randomized trial of short- versus longcourse radiotherapy for palliation of painful bone metastases. J Natl Cancer Inst. 2005;97:798-804.

26. van der Linden YM, Lok JJ, Steenland E, et al. Single fraction radiotherapy is efficacious: a further analysis of the Dutch Bone Metastasis Study controlling for the influence of retreatment. Int J Radiat Oncol Biol Phys. 2004;59:528-37.

27. Nguyen J, Chow E, Zeng L, et al. Palliative response and functional interference outcomes using the Brief Pain Inventory for spinal bony metastases treated with conventional radiotherapy. Clin Oncol (R Coll Radiol). 2011;23:485-91.

28. Wu JS, Monk G, Clark T, et al. Palliative radiotherapy improves pain and reduces functional interference in patients with painful bone metastases: a quality assurance study. Clin Oncol (R Coll Radiol). 2006;18:539-44.

29. Quinten C, Coens C, Mauer M, et al. Baseline quality of life as a prognostic indicator of survival: a meta-analysis of individual patient data from EORTC clinical trials. Lancet Oncol. 2009:10:865-71.

\section{Submit your next manuscript to BioMed Central and take full advantage of:}

- Convenient online submission

- Thorough peer review

- No space constraints or color figure charges

- Immediate publication on acceptance

- Inclusion in PubMed, CAS, Scopus and Google Scholar

- Research which is freely available for redistribution 